\title{
Impact of theory-based educational intervention on explaining preventive pediculosis infestation behavior among primary school students
}

\author{
Robab Sharifat ${ }^{1}$, Hashem Mohamadian ${ }^{2}$, Maria Cheragi $^{3}$, Amal Saki Malehi $^{4}$
}

${ }^{1}$ M.Sc. Student of Health Education, Faculty of Health, Department of Health Education, Ahvaz Jundishapur University of Medical Sciences, Ahvaz, Iran

${ }^{2}$ Ph.D. of Health Education, Assistant Professor, Social Determinant of Health Research Center, Department of Health Education, Faculty of Health, Ahvaz Jundishapur university of Medical Sciences, Ahvaz, Iran

${ }^{3} \mathrm{Ph}$.D. of Health Science, Associate Professor, Social Determinant of Health Research Center, Department of Public Health, Faculty of Health, Ahvaz Jundishapur university of Medical Sciences, Ahvaz, Iran

${ }^{4}$ Ph.D. of Biostatistics, Assistant Professor, Department of Biostatistics and Epidemiology, Faculty of Health, Ahvaz Jundishapur University of Medical Sciences, Ahvaz, Iran

\section{Type of article: Original}

\begin{abstract}
Background: Despite the fact that improved health, social, and economic situations have significantly affected the reduction of its infestation, pediculosis is still spreading worldwide.

Aim: This study is conducted to evaluate the explanatory power of health belief model constructs in adoption of preventive pediculosis infestation behavior in female primary school students.

Methods: This study involves two stages. First, a cross-sectional study was conducted. In the second stage, a quasi-experimental intervention was performed. One hundred eighty female elementary school students in Omidiyeh County were randomly selected in two 90-subject groups (experimental and control). Samples were matched in two groups in terms of demographic variables. A group of educational intervention was based on the most effective construct of the first stage; and the educational intervention of control group was based on the loweffective construct. The path analysis and LISREL 8.5 software was utilized to compare the fit and the variance cover percentage of adopting preventive pediculosis infestation behaviors.

Results: According to the pre-intervention findings, there was no significant difference between experimental and control groups in terms of factors affecting the adoption of preventive pediculosis infestation behavior. This model had a weaker fit in the experimental than the control group, but these indices had better status after intervention in the experimental than the control group. Meanwhile, the cover percentage of explained variance for the experimental group after educational intervention was higher than pre-intervention, but it was lower in the control group. Finally, health belief model constructs (including the knowledge, cue to action, perceived susceptibility and severity, perceived benefits and barriers, and self-efficacy) in the experimental group, had better fit after the educational intervention compared with pre-intervention.

Conclusion: Efficiency of the health belief model was approved for adopting preventive pediculosis infestation behavior in female primary school students. The future intervention studies should utilize the structural equation modeling approach separately in experimental and control groups to compare the changes in behavior between different demographic groups in the field of pediculosis infestation behavior.

Keywords: Pediculosis, Health belief model, Path analysis
\end{abstract}

\section{Introduction}

Louse is an external parasite of the human body and can infect the head, body, and sexual organs (1). Head louse has been viewed as a public health problem in the world (2). According to the National Center for Prevention of Head

\section{Corresponding author:}

Assistant Professor Dr. Hashem Mohamadian, Faculty of Health, Ahvaz Jundishapur university of Medical Sciences, Ahvaz, Iran. Tel: +98.9133716791, Email: hmohamadian@razi.tums.ac.ir

Received: July 10, 2016, Accepted: October 26, 2016, Published: April 2017

iThenticate screening: October 07, 2016, English editing: February 22, 2017, Quality control: March 12, 2017

(C) 2017 The Authors. This is an open access article under the terms of the Creative Commons Attribution-NonCommercialNoDerivs License, which permits use and distribution in any medium, provided the original work is properly cited, the use is non-commercial and no modifications or adaptations are made. 
Louse, the outbreak of head louse above $5 \%$ is epidemic (3). Despite the fact that improved health, social, and economic situations have significantly affected the reduction of its infestation, this parasite is still spreading worldwide (4). Six to 12 million people have been annually infected with this parasite in the United States, and its treatment and control have spent approximately $\$ 367$ million (1). Iran possesses the moderate outbreak of this infestation compared with other countries. The rate of its outbreak usually ranges from $2 \%$ to $7 \%$ in Iran, and it may be slightly increased due to the arrival of cold weather and environmental changes. Despite the rare outbreak of louse at some schools in the past, it has been seriously increased in recent years due to the diluted number of health educators (5). Students annually lose 12 to 24 million school days due to the head lice (6). The pediculosis infestation creates physical disorders in addition to psychological problems and transmitted secondary diseases for students and their family. Head louse is one of the most common health problems for primary school children and especially girls in the world (7). The medical literature has emphasized special talent of implantation by this parasite among primary school students, especially girls. Louse has always been significant due to close contact with humans and its potential for transmission of multiple diseases. Communities react differently to head louse infestation. Some communities show reactions to pediculosis infestation such as shock, blaming the child, isolating the child from others, and finally making efforts to eradicate it as soon as possible, while the other societies accept it as a normal condition, which does not require any treatment or preventative action. Thus, there is a need for extensive and comprehensive actions on the primary measures to eradicate and combat the louse and reduce the rate of infestation. Wet conditions and high population density have created a desirable environment for increased population of Louse in Khuzestan Province. It should be noted that people can prevent head louse through health education. The selection of the model or theory is one of the most important issues of educational interventions. The selection of an educational model leads to start the program and its continuation in a right direction. The Health Belief Model is one of the current educational models. This model emphasizes how the individual perception leads to motivation and movement and creates the behavior (8). Therefore, we have decided to identify the main determinants of this model through a theoretical framework of the health belief model with a structural equation modeling approach and use it for designing the educational intervention program in order to adopt preventive health behavior, especially for female primary school students in Omidiyeh County. This study is conducted with the aim of evaluating the explanatory power of health belief model constructs in adoption of preventive Pediculosis infestation behavior among female primary school students.

\section{Material and Methods}

This study involves two stages. First, a cross-sectional study was conducted to design change behavior strategies based on a health belief model and achieve an appropriate educational model. In the second stage, a quasiexperimental intervention was performed to evaluate and compare the indices of a fitted health belief model to adopt the preventive pediculosis infestation behavior among female students in Omidiyeh County during 2015. The statistical population of this study consisted of female elementary school students in Omidiyeh County. The multistage sampling method was used for sampling, so that health centers by county were selected as clusters, and four of them were randomly included in the study based on the infestation situation at each school and also distribution of schools around the health centers and similarity of health status at each school. One hundred and eighty students were randomly measured in two 90 -subject groups (exprimental and control). The education method for the intervention group was based on the results of needs assessment in stage before the intervention. Samples were matched in two groups in terms of demographic variables. According to the situation of schools and the learners' capacity, the researchers designed and developed the most important tips and preventive measures of pediculosis infestation in the forms of further and less effective constructs. A group of educational intervention was based on the most effective construct of the first stage; and the educational intervention of control group was based on the low-effective construct. The contents were presented by designing and applying the booklet, holding multiple meetings with their active participation in discussions, holding several motivational group interviews, empowering the individual skills during numerous meetings, and their active participation in the preparation of educational posters. Following an initial needs assessment in the form of pre-test, the intervention was done in experimental groups, and then the final assessment was conducted in two groups three months later. Education was done through group training method. Data were collected after obtaining consent from students and their parents in the presence of hygiene expert at schools and through interviews. In this study, the data collection tool was an extracted standardized questionnaire based on previous similar studies. The 4-point Likert scale (strongly agree, agree, disagree, and strongly disagree) was utilized to evaluate each item. Participants' demographic information (age, gender, parents' education levels and job, place of residence, and use of common clothing, bathing frequency per week, hair condition, etc.) were also evaluated. According to the current standard (Booklet of "Combating Louse at Schools" published by the Health Department of Ministry of Health and Medical Education), the diagnosis of 
pediculosis infestation was based on live egg, nymph, and adult egg. Hair (especially behind the ears and on the neck) was examined in the presence of sufficient light for about 3 minutes. It should be noted that the examination of student's head was done through direct observation by magnifying glass; and the suspected student was asked to comb her hair by a fine comb on a white paper, and then the paper was investigated. To ensure the diagnosis, the students' hair was examined under a microscope in a laboratory. The content and face validity of the questionnaire was evaluated by panel of research experts. The test-retest used to investigate the reliability and internal stability. Thus, 25 primary school students responded to questionnaires twice within 20 days. The path analysis and LISREL 8.5 Software was utilized to compare the fit indices and variance cover percentage of adopting preventive pediculosis infestation behaviors (9). The fit indices of this study were including chi-square per degrees of freedom; normed fit index (NFI); non-normed fit index (NNFI); comparative fit index (CFI); goodness of fit index (GFI); root mean square error of approximation (RMSEA), and ultimately, the standardized root mean square residual (SRMR) (10). In this study, the data analysis was done by statistical SPSS16 software (11) and LISREL 8.5 software (12). The chi-square test was used to assess the qualitative variables; and the path analysis test was applied to compare the effect of educational intervention in both experimental and control groups and also before and after the intervention.

\section{Results}

According to the pre-intervention findings, there was no significant difference between experimental and control groups in terms of factors affecting the adoption of preventive pediculosis infestation behavior (including age, father's job, parents' educational levels, experience of pediculosis infestation). The students' age average before intervention was $11.5 \pm 1.5$ years. According to chi-square test results, there was no statistically significant difference between the students' age in the experimental and control groups $(\mathrm{p}=0.74)$. Based on the chi-square test, there was no statistically significant difference between both two groups in terms of fathers' educational levels $(\mathrm{p}=0.11)$. Furthermore, the research findings indicated that the majority of student's fathers were self-employed. Also, the majority of students' fathers had passed secondary and high school education levels. Based on the chi-square test, there was no statistically significant difference between both groups in terms of mothers' educational levels $(\mathrm{p}=0.50)$. According to research findings, most of the students' mothers had passed secondary and high school education levels. Despite the fact that the majority of students were infected with pediculosis in the last three months, there was no significant difference between both groups in terms of pediculosis infestation based on chisquare test $(\mathrm{p}=0.06)$. According to results of path analysis on health belief model indices in adopting preventive pediculosis infestation behavior in experimental and control groups before intervention, this model had a weaker fit in the experimental group than the control group, but these indices had better status after intervention in the experimental group than the control group (Table 1).

Table 1. Health belief model's fit indexes in adopting preventive pediculosis infestation behavior in experimental and control groups before and after educational intervention

\begin{tabular}{|l|l|l|l|l|}
\hline \multirow{2}{*}{ Fit Indexes } & \multicolumn{4}{|l|}{ Groups } \\
\cline { 2 - 5 } & \multicolumn{2}{|l|}{ Experimental } & \multicolumn{2}{l|}{ Control } \\
\cline { 2 - 5 } & Before & After & Before & After \\
\hline$\chi^{2}$ & 6.71 & 2.95 & 7.80 & 10.15 \\
\hline $\mathrm{df}$ & 6 & 6 & 6 & 6 \\
\hline$\chi^{2} / \mathrm{df}$ & 1.11 & 0.49 & 1.3 & 1.69 \\
\hline $\mathrm{p}$-value & 0.348 & 0.814 & 0.252 & 0.118 \\
\hline RMSEA & 0.34 & 0.000 & 0.064 & 0.0820 \\
\hline CFI & 0.97 & 1 & 0.98 & 0.98 \\
\hline GFI & 0.98 & 0.98 & 0.98 & 0.98 \\
\hline NFI & 0.85 & 0.94 & 0.91 & 0.89 \\
\hline SRMR & 0.051 & 0.042 & 0.046 & 0.04 \\
\hline AIC & 70.15 & 62.95 & 66.71 & 67.80 \\
\hline Variance coverage $\left(\mathrm{R}^{2}\right)$ & 0.16 & 0.36 & 0.35 & 0.20 \\
\hline
\end{tabular}

Meanwhile, the cover percentage of explained variance for adoption of preventive pediculosis infestation behavior in the experimental group after educational intervention was higher than pre-intervention, but it was lower in the control group. Finally, according to results of path analysis on fit indices of health belief model constructs (including the knowledge, cue to action, perceived susceptibility and severity, perceived benefits and barriers, and selfefficacy) in adopting preventive pediculosis infestation behavior in the experimental group, these indices had better 
fit after the educational intervention compared to pre-intervention (Table 2). The comparison constructs explaining the preventive pediculosis infestation behavior in the experimental group before and after the educational intervention indicated the impact of educational intervention and improvement of model fit indices in experimental group. Furthermore, the results of path analysis on fit indices of health belief model constructs (including the knowledge, cue to action, perceived susceptibility and severity, perceived benefits, barriers and self-efficacy) in adopting preventive pediculosis infestation behavior in the control group indicated the good fit of these indices before intervention compared to post- intervention (Table 3). The comparison constructs explaining the preventive pediculosis infestation behavior in the control group before and after the educational intervention indicated a drop in explanation rate and weaknesses of model fit in the control group.

Table 2. Comparison of health belief model construct's fit indexes in the experimental group before and after educational intervention

\begin{tabular}{|c|c|c|}
\hline Fit Indexes & Before & After \\
\hline Knowledge & $\begin{array}{l}\chi^{2}=46.10, \mathrm{df}=27, \mathrm{p}-\mathrm{value}=0.012 \\
\mathrm{CFI}=0.81, \mathrm{GFI}=0.81, \mathrm{RMSEA}=0.081\end{array}$ & $\begin{array}{l}\chi^{2}=40.95, \mathrm{df}=27, \mathrm{p} \text {-value }=0.041, \\
\mathrm{CFI}=0.83, \mathrm{GFI}=0.91, \mathrm{RMSEA}=0.011\end{array}$ \\
\hline Cue to action & $\begin{array}{l}\chi^{2}=23.03, \mathrm{df}=2, \mathrm{p} \text {-value }=0.00, \mathrm{CFI}=0.67 \\
\mathrm{GFI}=0.87, \mathrm{RMSEA}=0.363\end{array}$ & $\begin{array}{l}\chi^{2}=0.10, \mathrm{df}=2, \mathrm{p} \text {-value }=0.95, \mathrm{CFI}=1, \\
\mathrm{GFI}=1, \mathrm{RMSEA}=0.000\end{array}$ \\
\hline $\begin{array}{l}\text { Perceived } \\
\text { susceptibility }\end{array}$ & $\begin{array}{l}\chi^{2}=6.95, \mathrm{df}=5, \mathrm{p}-\mathrm{value}=0.22, \mathrm{CFI}=0.99 \\
\mathrm{GFI}=0.98, \mathrm{RMSEA}=0.060\end{array}$ & $\begin{array}{l}\chi^{2}=2.31, \mathrm{df}=5, \mathrm{p} \text {-value }=0.80, \mathrm{CFI}=1, \\
\mathrm{GFI}=0.98, \mathrm{RMSEA}=0.000\end{array}$ \\
\hline $\begin{array}{l}\text { Perceived } \\
\text { severity }\end{array}$ & $\begin{array}{l}\chi^{2}=15.39, \mathrm{df}=5, \mathrm{p}-\mathrm{value}=0.008, \mathrm{CFI}=0.93, \\
\mathrm{GFI}=0.91, \mathrm{RMSEA}=0.138\end{array}$ & $\begin{array}{l}\chi^{2}=9.67, \mathrm{df}=5, \mathrm{p} \text {-value }=0.85, \mathrm{CFI}=0.95, \\
\mathrm{GFI}=0.95, \mathrm{RMSEA}=0.155\end{array}$ \\
\hline Perceived benefits & $\begin{array}{l}\chi^{2}=15.18, \mathrm{df}=5, \mathrm{p}-\mathrm{value}=0.009, \mathrm{CFI}=0.81, \\
\mathrm{GFI}=0.95, \mathrm{RMSEA}=0.137\end{array}$ & $\begin{array}{l}\chi^{2}=3.32, \mathrm{df}=5, \mathrm{p} \text {-value }=0.65, \mathrm{CFI}=1 \\
\mathrm{GFI}=0.98, \mathrm{RMSEA}=0.000\end{array}$ \\
\hline Perceived barriers & $\begin{array}{l}\chi^{2}=8.31, \mathrm{df}=5, \mathrm{p}-\mathrm{value}=0.139, \mathrm{CFI}=0.98 \\
\mathrm{GFI}=0.96, \mathrm{RMSEA}=0.078\end{array}$ & $\begin{array}{l}\chi^{2}=4.19, \mathrm{df}, 5, \mathrm{pvalue}=0.522, \mathrm{CFI}=1 \\
\mathrm{GFI}=0.97, \mathrm{RMSEA}=0.000\end{array}$ \\
\hline Self-efficacy & $\begin{array}{l}\chi^{2}=18.37, \mathrm{df}=5, \mathrm{p}-\mathrm{value}=0.002, \mathrm{CFI}=0.70, \\
\mathrm{GFI}=0.90, \mathrm{RMSEA}=0.16\end{array}$ & $\begin{array}{l}\chi^{2}=1.54, \mathrm{df}=5, \mathrm{p} \text {-value }=0.82, \mathrm{CFI}=1, \\
\mathrm{GFI}=0.99, \mathrm{RMSEA}=0.000\end{array}$ \\
\hline
\end{tabular}

Table 3. Comparison of health belief model construct's fit indexes in the control group before and after educational intervention

\begin{tabular}{|c|c|c|}
\hline Fit Indexes & Before & After \\
\hline Knowledge & $\begin{array}{l}\chi^{2}=51.38, \mathrm{df}=27, \mathrm{p} \text {-value }=0.003, \mathrm{CFI}=0.70, \\
\mathrm{GFI}=0.88, \mathrm{RMSEA}=0.106\end{array}$ & $\begin{array}{l}\chi^{2}=76.18, \mathrm{df}=27, \mathrm{p} \text {-value }=0.00, \mathrm{CFI}=0.63, \\
\mathrm{GFI}=0.87, \mathrm{RMSEA}=0.129\end{array}$ \\
\hline Cue to action & $\begin{array}{l}\chi^{2}=0.55, \mathrm{df}=2, \mathrm{p} \text {-value }=0.758, \mathrm{CFI}=1 \\
\mathrm{GFI}=1, \mathrm{RMSEA}=0.000\end{array}$ & $\begin{array}{l}\chi^{2}=4.05, \mathrm{df}=2, \mathrm{p}-\mathrm{value}=0.13, \mathrm{CFI}=0.97 \\
\mathrm{GFI}=0.95, \mathrm{RMSEA}=0.16\end{array}$ \\
\hline $\begin{array}{l}\text { Perceived } \\
\text { susceptibility }\end{array}$ & $\begin{array}{l}\chi^{2}=8.46, \mathrm{df}=5, \mathrm{p} \text {-value }=0.132, \mathrm{CFI}=0.94 \\
\mathrm{GFI}=0.97, \mathrm{RMSEA}=0.080\end{array}$ & $\begin{array}{l}\chi^{2}=11.79, \mathrm{df}=5, \mathrm{p}-\text { value }=0.037, \mathrm{CFI}=0.92 \\
\mathrm{GFI}=0.94, \mathrm{RMSEA}=0.13\end{array}$ \\
\hline $\begin{array}{l}\text { Perceived } \\
\text { severity }\end{array}$ & $\begin{array}{l}\chi^{2}=13, \mathrm{df}=5, \mathrm{p}-\mathrm{value}=0.023, \mathrm{CFI}=0.91 \\
\mathrm{GFI}=0.95, \mathrm{RMSEA}=0.122\end{array}$ & $\begin{array}{l}\chi^{2}=37.31, \mathrm{df}=5, \mathrm{p} \text {-value }=0.00, \mathrm{CFI}=0.74 \\
\mathrm{GFI}=0.84, \mathrm{RMSEA}=0.284\end{array}$ \\
\hline Perceived benefits & $\begin{array}{l}\chi^{2}=15.80, \mathrm{df}=5, \mathrm{p}-\mathrm{value}=0.007, \mathrm{CFI}=0.90, \\
\mathrm{GFI}=0.95, \mathrm{RMSEA}=0.141\end{array}$ & $\begin{array}{l}\chi^{2}=24.83, \mathrm{df}=5, \mathrm{p} \text {-value }=0.00, \mathrm{CFI}=0.68 \\
\mathrm{GFI}=0.80, \mathrm{RMSEA}=0.319\end{array}$ \\
\hline Perceived barriers & $\begin{array}{l}\chi^{2}=4.15, \mathrm{df}=5, \mathrm{p} \text {-value }=0.52, \mathrm{CFI}=1 \\
\mathrm{GFI}=0.98, \mathrm{RMSEA}=0.000\end{array}$ & $\begin{array}{l}\chi^{2}=4.45, \mathrm{df}=5, \mathrm{p} \text {-value }=0.48, \mathrm{CFI}=0.98 \\
\mathrm{GFI}=0.84, \mathrm{RMSEA}=0.000\end{array}$ \\
\hline Self-efficacy & $\begin{array}{l}\chi^{2}=10.51, \mathrm{df}=5, \mathrm{p} \text {-value }=0.62, \mathrm{CFI}=0.77 \\
\mathrm{GFI}=0.94, \mathrm{RMSEA}=0.16\end{array}$ & $\begin{array}{l}\chi^{2}=26.86, \mathrm{df}=5, \mathrm{p} \text {-value }=0.00, \mathrm{CFI}=0.79 \\
\mathrm{GFI}=0.91, \mathrm{RMSEA}=0.2\end{array}$ \\
\hline
\end{tabular}

\section{Discussion}

This study is conducted with the aim of evaluating the explanatory power of health belief model constructs in adoption of preventive pediculosis infestation behavior among female primary school students. The research findings shown the useful of educational intervention based on the health belief model constructs in adoption of preventive pediculosis infestation behavior. In current study, the fit indices of constructs such as the perceived susceptibility and severity, cue to action, perceived benefits, and self-efficacy were improved after the educational intervention in the experimental group; subsequently, the explanation rate of preventive pediculosis infestation behavior was significantly increased. A few studies have investigated the effect of the health belief model constructs for improving the explanation rate of preventive behavior using structural equation modeling approach. Those 
studies which have evaluated the educational interventions through structural equation modeling approach, have used the total sample (both experimental and control groups together) $(13,14)$. But, each group should be separately evaluated for estimating the variance of explanation rate. In other words, we can find out whether or not the educational intervention is appropriate for fitting adopted behavior in the experimental group rather than control group. Current study properly covers this weakness in existing studies. This study is the first study that has utilized the health belief model constructs as educational intervention in both experimental and control group using structural equation modeling approach. Structural equation modeling approach helps the researcher to identify the major determinants for design the educational intervention program in adoption of preventive behavior. According to the literature review, studies which use the theory as their educational interventions framework was more effective than other non-theoretical interventions; this justifies the increased influence of theory-based interventions by mandatory mechanisms. The behavior change mediators are effective in facilitating the intervention to achieve the desired behavioral outcomes. Those are particularly important in build the effective interventions because they enable the researchers to use the most important and effective components in the intervention and elimination of unnecessary factors. Few studies was used of health belief model constructs for changing the preventive pediculosis infestation behavior. Current results indicate that adoption of preventive pediculosis infestation behavior had a direct relationship with perceived susceptibility and self-efficacy in this research but indirect relationships with other health belief model constructs. In this study, the self-efficacy was the best behavior determinant factor. The selfefficacy can help to people to improve the health behavior such as the prevention of pediculosis infestation. Higher self-efficacy enables people to meet the standard recommendations in their personal hygiene. Self-efficacy is an important explanation construct in the many interventions $(16,17)$. Furthermore, the self-efficacy of preventive and health promoting behavior is among the most common evaluated mediators; its role and impact as a mediator in behavioral change have gained a lot of support (18). The results of current research re-support the impact of perceived self-efficacy on increases in health promotion behavior such pediculosis infestation prevention. Students who have better beliefs and behavioral skills also have healthier behavior. Preventive behavior based on personal beliefs is included in the health belief model, which covers the vulnerability to disease, the impact of disease on life, and effect of health measures on reducing disease susceptibility and severity; most of the studies that use the health belief model now focus on these variables (19). Moshki et al. (2013) had used the health belief model for improving the preventive pediculosis infestation behavior (15). According to Moshki et al., there was a significant correlation between preventive pediculosis infestation behavior with perceived barriers and self-efficacy constructs. Current study, the educational intervention on specific behavior cognitions (self-efficacy, perceived severity, susceptibility, benefits and barriers, the cue to action for pediculosis infestation prevention) have almost increased the significance of the mean scores of target variables in the experimental group. In this study, the educational intervention has significantly increased the mean score of perceived susceptibility and self-efficacy for preventive pediculosis infestation behavior. This result is consistent with findings of other studies $(20,21)$. There was no significant difference between two groups before the intervention in terms of health belief model constructs. Thus, this change can be attributed to educational intervention based on the assessment of both groups using structural equation modeling approach at a high confidence level. The literature review emphasizes the impact of interpersonal factors (cue to action) on preventive behavior (22). According to some studies, teachers and families not had sufficient and equipped information to control the head louse infestation (23). Therefore, educational interventions should focus on teachers and students' families to give their students an understanding of pediculosis infestation risk. Thus, if we want to strengthen the interpersonal factors (cue to action) affecting the preventive behavior in students, we should provide observational learning and positive modeling opportunities in order to change the family members and teacher's behavior affecting their students. This phenomenon cannot be easily achieved and requires long-term training through various and new educational methods. It seems that the change in interpersonal factors is challenging, and the short-term interventions do not have an appropriate and sustainable impact of these factors.

\section{Conclusions}

Educational intervention using health belief model framework could improve and promote the fit indices in adopting preventive pediculosis infestation behavior in the experimental group rather than the control group. Also, it increased the explanation rate for adoption of preventive pediculosis infestation behavior in the experimental group compared with the control group after the intervention. Therefore, the efficiency of the health belief model was approved for adopting preventive pediculosis infestation behavior in female primary school students. Future intervention studies should utilize the structural equation modeling approach separately in experimental and control groups to compare the changes in behavior between different demographic groups in the field of health promotion behaviours. 


\section{Acknowledgments:}

This paper is the outcome of a research project approved at the Ahvaz Jundishapur University of Medical Sciences (AJUMS) with the number of SDH-9419. We hereby appreciate the assistance of the research deputy and management of the university and also the manager and personnel at the Office of Education and all people who helped us gather the information.

\section{Conflict of Interest:}

There is no conflict of interest to be declared.

\section{Authors' contributions:}

All authors contributed to this project and article equally. All authors read and approved the final manuscript.

\section{References:}

1) Sangaré AK, Doumbo OK, Raoult D. Management and treatment of human lice. BioMed Research International. 2016; 2016. doi: 10.1155/2016/8962685.

2) Yousefi S, Shamsipoor F, Abadi YS. Epidemiological study of head louse (Pediculus humanus capitis) infestation among primary school students in rural areas of Sirjan County, South of Iran. Thrita. 2012; 1(2): 53-6. doi: 10.5812/thrita. 4733.

3) Toloza A, Vassena C, Gallardo A, González-Audino P, Picollo MI. Epidemiology of Pediculosis capitis in elementary schools of Buenos Aires, Argentina. Parasitol Res. 2009; 104(6): 1295-8. doi: 10.1007/s00436008-1324-6. PMID: 19148682.

4) Malcolm CE, Bergman JN. Trying to keep ahead of lice: a therapeutic challenge. Skin Therapy Lett. 2006; 11(10): 1-6. doi: 10.1371/journal.pbio.0020340. PMID: 17180245.

5) Dehghani R, Davari B, Moosavi SG, Eslami h, Kachoei E, Rahimi M, et al. Prevalence of head lice infestation among 3-6 years old nursery children in Kashan (2009). Journal of Occupational Health and Epidemiology. 2012; 1(2): 81-6.

6) Kelly SA, Melnyk BM, Jacobson DL, O'Haver JA. Correlates among healthy lifestyle cognitive beliefs, healthy lifestyle choices, social support, and healthy behaviors in adolescents: Implications for behavioral change strategies and future research. J Pediatr Health Care. 2011; 25(4): 216-23. doi: 10.1016/j.pedhc.2010.03.002. PMID: 21700136.

7) Salehi S, Ban M, Motaghi M. A study of head lice infestation (Pediculosis capitis) among primary school students in the villages of Abadan in 2012. Int J Community Based Nurs Midwifery. 2014; 2(3): 196-200. PMID: 25349862, PMCID: PMC4201201.

8) Green EC, Murphy E. Health belief model. The Wiley Blackwell Encyclopedia of Health, Illness, Behavior, and Society. 2014. doi: 10.1002/9781118410868.wbehibs410.

9) Byrne BM. Structural equation modeling with LISREL, PRELIS, and SIMPLIS: Basic concepts, applications, and programming: Psychology Press; 2013.

10) Henseler J, Sarstedt M. Goodness-of-fit indices for partial least squares path modeling. Computational Statistics. 2013; 28(2): 565-80. doi: 10.1007/s00180-012-0317-1.

11) Kirkpatrick L, Feeney B. A simple guide to SPSS for Version 16.0: Cengage Learning; 2008.

12) Du Toit M, Du Toit SHC, Hawkins DM. Interactive LISREL: User's guide: Scientific Software International; 2001.

13) Amirzadeh Iranagh J, Motallebi A. The effect of health belief model based on education intervention on physical activity of elderly women. J Urmia Nurs Midwifery Fac. 2016; 13(12): 1050-8.

14) Esmaeily H, Peyman N, Taghipour A, KHorashadizadeh F, Mahdizadeh M. A Structural Equation Model to predict the Social-Cognitive Determinants related to Physical Activity in Iranian women with Diabetes Mellitus. J Res Health Sci. 2014; 14(4): 296-302. PMID: 25503287.

15) Moshki M, Mojadam M, Zamani Alavijeh F. Preventive Behaviors of Female Elementary Students in regard to Pediculosis Infestation based on Health Belief Model (HBM). Journal of health and development. 2014; 3(3): 269-0.

16) Schwarzer R, Antoniuk A, Gholami M. A brief intervention changing oral self-care, self-efficacy, and selfmonitoring. Br J Health Psychol. 2015; 20(1): 56-67. doi: 10.1111/bjhp.12091. PMID: 24471473.

17) Otsuka K, Taguri M, Dennis CL, Wakutani K, Awano M, Yamaguchi T, et al. Effectiveness of a breastfeeding self-efficacy intervention: do hospital practices make a difference? Matern Child Health J. 2014; 18(1): 296-306. doi: 10.1007/s10995-013-1265-2. PMID: 23592322, PMCID: PMC3880483. 
18) Luszczynska A, Hagger MS, Banik A, Horodyska K, Knoll N, Scholz U. Self-efficacy, planning, or a combination of both? A longitudinal experimental study comparing effects of three interventions on adolescents' body fat. PloS one. 2016; 11(7): e0159125. doi: 10.1371/journal.pone.0159125. PMID: 27410961, PMCID: PMC4943603.

19) Schwarzer R. Self-efficacy: Thought control of action: Taylor \& Francis; 2014.

20) Morowati Sharifabad MA, Ebrahim Zadeh M, Fazeli F, Dehghani A, Neshati T. Study of Pediculus capitis prevalence in primary school children and its preventive behaviors determinants based on Health Belief Model in Their Mothers in Hashtgerd, 2012. Tolooebehdasht. 2016; 14(6): 198-207.

21) Gholamnia Shirvani Z, Amin Shokravi F, Ardestani MS. Evaluation of a health education program for head lice infestation in female primary school students in Chabahar City, Iran. Arch Iran Med. 2013; 16(1): 42-5. doi: 013161/AIM.0013. PMID: 23273236.

22) Reisi M, Javadzade SH, Shahnazi H, Sharifirad G, Charkazi A, Moodi M. Factors affecting cigarette smoking based on health-belief model structures in pre-university students in Isfahan, Iran. J Educ Health Promot. 2014; 3: 23. doi: 10.4103/2277-9531.127614. PMID: 24741663, PMCID: PMC3977390.

23) Ibarra J, Fry F, Clarice W, Olsen A, Vander Stichele RH, Lapeere H, et al. Overcoming health inequalities by using the Bug Busting 'whole-school approach to eradicate head lice. J Clin Nurs. 2007; 16(10): 1955 65. doi: 10.1111/j.1365-2702.2007.01795.x. PMID: 17880484. 